\title{
Genotype Distributions and Allele Frequencies of Possible Major Depressive Disorder-Associated Single Nucleotide Polymorphisms, Cyclic Adenosine Monophosphate Response Element Binding Protein 1 rs4675690 and Piccolo rs2522833, in a Japanese Population
}

\author{
Kazuyuki Inoue, Natsuko Ando, Eri Suzuki, Hideki Hayashi, Daiki Tsuji, and Kunihiko Itoh* \\ Department of Clinical Pharmacology \& Genetics, School of Pharmaceutical Sciences, University of Shizuoka; 52-1 \\ Yada, Suruga-ku, Shizuoka 422-8526, Japan. \\ Received September 5, 2011; accepted November 11, 2011; published online November 14, 2011
}

\begin{abstract}
It is known that the onset of major depressive disorder (MDD) would be associated with genetic factors. To investigate the susceptibility to psychiatric disorders, e.g. MDD, schizophrenia etc., it is necessary to compare the genetic differences of objective polymorphisms between in patients and in relative contol subjects. Recently, an increasing number of studies focused on the role of cyclic adenosine monophosphate response element binding protein $1(C R E B 1)$ and Piccolo (PCLO) on MDD. However, there was no report about genetic characterization of polymorphisms in between MDD patients and healthy subjects in Japanese population. We analized genotype distributions and allele frequencies of $C R E B 1$ rs4675690 and PCLO rs2522833 polymorphisms in 267 Japanese subjects, respectively. In $C R E B 1$ rs4675690, $C$ allele frequency $(0.41)$ was lower than $T$ allele (0.59). While in $P C L O$ rs2522833, $A$ allele frequency $(0.45)$ was lower than $C$ allele $(0.55)$. Our findings may be useful for investigating the genetic factors concerning the susceptibility to MDD in Japanese population.
\end{abstract} disorder

Key words cAMP response element binding protein 1; Piccolo; polymorphism; Japanese; major depressive

Major depressive disorder (MDD) is a familial disorder and its familiarity mostly or entirely results from genetic influence. ${ }^{1)}$ To investigate disease susceptibility affected by genetic polymorphism, it is often performed with comparison of genotype distributions and allele frequencies of objective polymorphism in patients with in its relative control subjects.

Recently, an increasing number of studies focused on the role of transcription factor, cyclic adenosine monophosphate response element binding protein 1 (CREB1) and presynaptic cytomatrix protein, Piccolo (PCLO) on MDD. CREB1 was reported that the association with neuronal signal transduction involved in synaptic plasticity ${ }^{2)}$ and antidepressant response. ${ }^{3,4)}$ In Caucasian population, CREB1 rs4675690 polymorphism was associated with anger expression in male MDD patients ${ }^{5)}$ and suicidal behaivor in MDD patients. ${ }^{6)}$ While PCLO was localized in the presynaptic active zone ${ }^{7)}$ and involved in monoamine neurotransmission. ${ }^{8)}$ PCLO polymorphism rs2522833 was related with hypothalamic-pituitary-adrenocortical (HPA) regulation during antidepressant treatment and the susceptibility to MDD in Caucasian population. ${ }^{9}$

It was suggested that these polymorphisms may be associated with the susceptibility to MDD and therapeutic efficacy of antidepressants in Japanese population. However there was no report about CREB1 rs4675690 and PCLO rs2522833 polymorphisms in Japanese population. In this study, we examined genotype distributions and allele frequencies of CREB1 rs4675690 and PCLO rs2522833 polymorphisms in 267 Japanese healthy subjects.

\section{MATERIALS AND METHODS}

Japanese Subjects This study was performed in accordance with the Declaration of Helsinki and Good Clinical Practice guidelines, and approved by the Ethics Committee of the University of Shizuoka, Shizuoka, Japan (approved number 18-2). A total of 267 Japanese subjects (137 males and 130 females, mean age $35.9 \pm 12.7$ years olds) were recruited. Written informed consent was obtained from an individual after a detailed briefing of the study purposes and protocols.

Genotyping Procedure Venous blood $(5 \mathrm{~mL})$ was obtained from a subject using ethylenediaminetetraacetic acid (EDTA)-2Na Venoject II tubes (Terumo, Tokyo, Japan). Leukocyte genomic DNA was extracted directly from the blood specimen using a QIAamp DNA Blood Mini Kit (Qiagen, Hilden, Germany) followed by its instruction. The genotype of $C R E B 1$ rs4675690 was analyzed by newly established allele-specific polymerase chain reaction (PCR)-based method. In brief, genomic DNA (100 ng) was amplified in PCR buffer containing $200 \mu \mathrm{M}$ deoxyribonucleotide triphosphate (dNTP) mixture (Applied Biosystems), $1 \mu \mathrm{M}$ each of forward primer (5'-CTC AAC CTC CTG AGT AGC TAG-3') and allele-specific reverse primer (for wild $A$ allele: $5^{\prime}$-TGT CTG ATC TGT TCT GTT TCA-3', for mutant $G$ allele: TGT CTG ATC TGT TCT GTT TCG-3'), 1.25 units HotStar Taq plus DNA polymerase (Qiagen), and $1.5 \mathrm{~mm} \mathrm{MgCl}_{2}$. Amplification was performed by i-Cycler thermal cycler (Bio-Rad, Hercules, CA, U.S.A.). The PCR condition consisted of an initial denaturation/enzyme activation step at $95^{\circ} \mathrm{C}$ for $5 \mathrm{~min}$, amplification for 33 cycles at $94^{\circ} \mathrm{C}$ for $30 \mathrm{~s}, 59^{\circ} \mathrm{C}$ for $30 \mathrm{~s}$, and $72^{\circ} \mathrm{C}$ for $30 \mathrm{~s}$ and final extension step at $72^{\circ} \mathrm{C}$ for $5 \mathrm{~min}$. The PCR products were electrophored on $3 \%$ agarose gel and genotype was identified by the appearance of amplified band (291 bp) either with wild $A$ allele reverse primer or with mutant $G$ allele reverse primer (Fig. 1a). Accuracy of allele-specific PCR method was confirmed by direct sequencing of PCR products amplified with primer sets (forward: 5'-TGG TGC GAT CTC AGC TCA CT-3', reverse: 5'-ATG TGA CTT ACT GCC TCT CAG-3') (Fig. 1b). 
a)

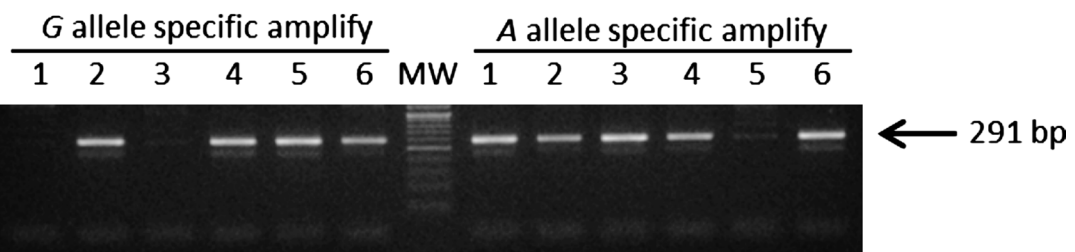

b)

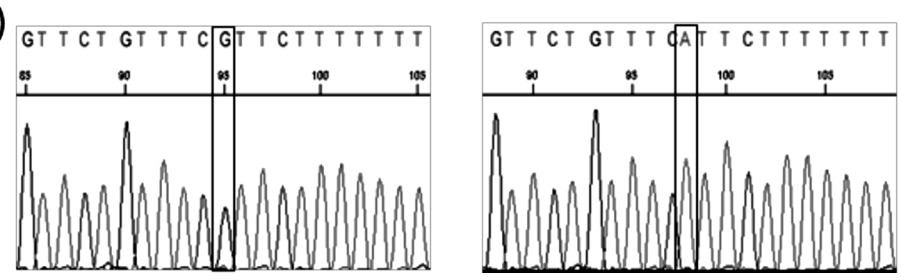

Fig. 1. Genotypes of CREB1 rs4675690 Polymorphism Were Determined by Allele-Specific PCR

(a) Genotype of 6 Japanese individuals was shown. Sample 5 is wild GG genotype. PCR product was amplified only in using $G$ allele specific primer. Samples 2,4 and 6 are hetero GA genotype. Both using $G$ allele-specific primer and $A$ allele-specific primer were amplified. Sample 1 is mutant AA genotype. PCR product was amplified only in using $A$ allele-specific primer. (b) The results of direct sequencing for wild GG and mutant AA individuals identified by allele-specific PCR. The results obtained by direct sequencing were coincided with those of allele-specific PCR.

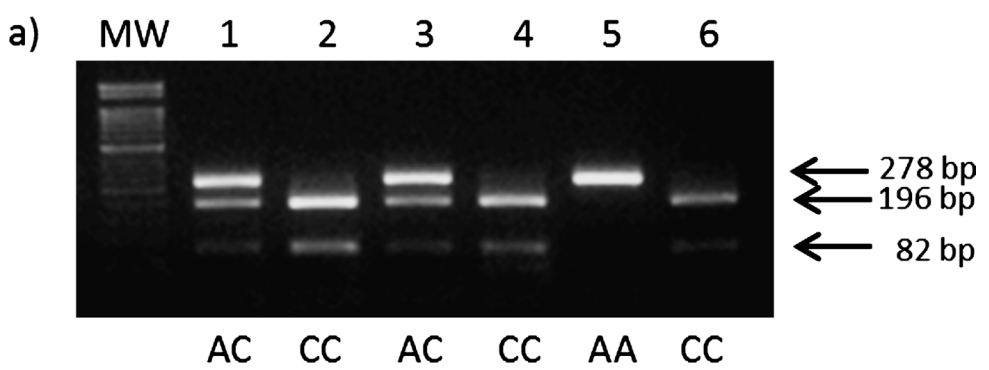

b)

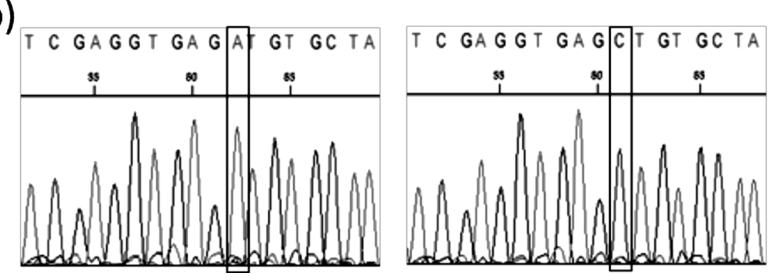

Fig. 2. Genotypes of PCLO rs2522833 Polymorphism Were Determined by PCR-RFLP

(a) Genotype of 6 Japanese individual was shown. Sample 5 is wild type AA, samples 1 and 3 are hetero type AC, samples 2 , 4 and 6 are mutant type CC. (b) The results of direct sequencing for wild AA and mutant CC individuals identified by PCR-RFLP. The accuracy of PCR-RFLP method was confirmed by direct sequencing.

The genotype of PCLO rs2522833 was determined by newly established PCR-restriction fragment length polymorphism (RFLP)-based method. In brief, genomic DNA (100ng) was amplified in PCR buffer containing $200 \mu \mathrm{M}$ dNTP mixture, $1 \mu \mathrm{M}$ each of forward primer (5'-TGA CTG GAA TGA GAC TTG CCA-3') and reverse primer (5'-GTT TCC AGT ATC ATT GGT GAA G-3'), 1.25 units HotStar Taq plus DNA polymerase, and $1.5 \mathrm{~mm} \mathrm{MgCl}_{2}$. Amplification was performed by i-Cycler thermal cycler. The PCR condition consisted of an initial denaturation/enzyme activation step at $95^{\circ} \mathrm{C}$ for $5 \mathrm{~min}$, amplification for 35 cycles at $94^{\circ} \mathrm{C}$ for $30 \mathrm{~s}, 57^{\circ} \mathrm{C}$ for $30 \mathrm{~s}$, and $72^{\circ} \mathrm{C}$ for $30 \mathrm{~s}$ and final extension step at $72^{\circ} \mathrm{C}$ for $10 \mathrm{~min}$. PCR products were digested by $A l u \mathrm{I}$ (New England BioLab., Beverly, Mass., U.S.A.). Digested products were electrophoresed on $3 \%$ agarose gel and the genotype was assigned by digestion patterns (wild $A$ allele: 278 bp, mutant $C$ allele: $196+82$ bp) (Fig. 2a). Accuracy of PCR-RFLP method was confirmed by direct sequencing of amplified PCR product
(Fig. 2b).

Statistical Analyses Genotype and allele frequencies were compared using the chi-square test with SPSS version 14.0 (SPSS Inc., Chicago, IL, U.S.A.). Differences were considered significant when $p<0.05$. Chi-square test was also used to compare results obtained with expected allele frequencies (Hardy-Weinberg equilibrium).

\section{RESULTS AND DISCUSSION}

In this paper, we firstly reported the genotype distributions and allele frequencies of CREB1 rs4675690 and PCLO rs2522833 polymorphisms in Japanese population. The results of CREB1 rs4675690 genotype distributions and allele frequencies were shown in Table 1. The wild CC genotype frequency was lower than that of mutant TT genotype in Japanese population. These results were in good accordance with the expected genotype distributions, calculated from 
Table 1. The Genotypes and Allele Frequencies of CREB1 rs4675690 and $P C L O$ rs2522833 Polymorphisms in Japanese Subjects

\begin{tabular}{ccrc}
\hline \hline Polymorphism & Genotype & $n(\%)$ & $\begin{array}{c}\text { Allele } \\
\text { frequency }\end{array}$ \\
\hline CREB1 rs4675690 & CC & $39(14.6)$ & C: 0.410 \\
& CC & $141(52.8)$ & T: 0.590 \\
PCLO rs2522833 & TT & $87(32.6)$ & \\
& AA & $47(17.6)$ & A: 0.448 \\
& AC & $145(54.3)$ & C: 0.552 \\
& CC & $75(28.1)$ & \\
\hline
\end{tabular}

Hardy-Weinberg equilibrium $(p=0.559)$. Serretti et al. reported that $C$ and $T$ allele frequencies in 76 healthy Caucasians were 0.61 and 0.39 , respectively. ${ }^{10)}$ In our study, $C$ and $T$ allele frequencies in Japanese population were 0.41 and 0.59 , respectively. It was known that CREB1 plays an important role in MDD and antidepressant treatment. ${ }^{2-4)}$ Although it is not clear the function at a molecular level in CREB1 rs4675690, Perlis et al. reported that individuals who are homozygous for the $T$ allele in rs4675690 were display less negative blood oxygenation level-dependent (BOLD) signals by functional magnetic resonance imaging (fMRI) than $C$ carriers for angry and fearful faces. ${ }^{11)}$ In other papers, Perlis et al. reported that $T$ allele in rs4675690 was associated with greater internal effort at anger control, greater risk of treatment-emergent suicidal ideation in MDD.,6) There were reports that depressed patients are significantly greater levels of anger than normal controls $^{12}$ ) and anger attacks are improved by antidepressant treatment. ${ }^{13)}$ Anger might overlap only partially with their effects on depression. ${ }^{14,15)} T$ allele frequency of $C R E B 1$ rs4675690 in Japanese is higher than in Caucasian. We suggest it is more necessary to analyze the genotype of rs 4675690 in between Caucasian and Japanese for examination of the susceptibility to MDD and the response of antidepressants. Moreover, it was known that the mutation of $5^{\prime}$ promoter of CREB1 gene was associated with the activation of cAMP pathway in culture cells. ${ }^{16)}$ Rs4675690 was located at the 5' region of CREB1 gene ${ }^{4)}$ and may associate with the regulation of CREB1 expression. It was necessary to investigate the molecular function and the influence to MDD susceptibility in rs4675690. On the other hand, the results of PCLO rs 2522833 genotype distributions and allele frequencies were shown in Table 1. The wild AA genotype frequency was lower than that of mutant CC genotype in Japanese population. These results were in good accordance with the expected genotype distributions, calculated from Hardy-Weinberg equilibrium $(p=0.735)$. PCLO rs2522833 was known as a non-synonymous coding polymorphism in the $\mathrm{C} 2 \mathrm{~A}$ calcium-binding-domain of PCLO. There was a report that overexpression of PCLO $\mathrm{C} 2 \mathrm{~A}$ domain induced depression like behavior in transgenic mouse. ${ }^{17)} C$ allele in rs2522833 is suggested as a causal risk factor for MDD in Caucasian. ${ }^{18)}$ Although it is not clear the function at a molecular level in rs2522833, Schuhmacher et al. reported that this polymorphism is associated with HPA system to antidepressant treatment in MDD. ${ }^{9)}$ They reported that the individuals of homozygous for the $A$ allele in rs 2522833 only displayed a decrease of cortisol and adrenocorticotropic hormone (ACTH) values during antidepressant treatment, whereas $C$ allele carriers did not. In Caucasian population, $C$ allele frequency of MDD and healthy population were 0.49 and 0.43 respectively. ${ }^{14)}$ In our study, $C$ allele frequency in Japanese population was 0.55 . $C$ allele frequency in rs 2522833 in Japanese is higher than in Caucasian. We suggest it may be more important to analyze the genotype of rs 2522833 in Japanese than in Caucasian for examination of the susceptibility to MDD and the response of antidepressants. We consider that it is necessary to investigate genetic frequencies of CREB1 rs4675690 and PCLO rs2522833, respectively, in MDD. Genotype distributions and allele frequencies of CREB1 rs4675690 and PCLO rs2522833 reported in this paper would be useful for examining the susceptibility to MDD in Japanese population.

Acknowledgment This study was supported in part by Grants-in-Aid for Young Scientists (B) from the Ministry of Education, Culture, Sports, Science and Technology of Japan.

\section{REFERENCES}

1) Sullivan PF, Neale MC, Kendler KS. Genetic epidemiology of major depression: review and meta-analysis. Am. J. Psychiatry, 157, 1552-1562 (2000).

2) Warburton EC, Glover CP, Massey PV, Wan H, Johnson B, Bienemann A, Deuschle U, Kew JN, Aggleton JP, Bashir ZI, Uney $\mathrm{J}$, Brown MW. cAMP responsive element-binding protein phosphorylation is necessary for perirhinal long-term potentiation and recognition memory. J. Neurosci., 25, 6296-6303 (2005).

3) Schwaninger M, Schöfl C, Blume R, Rössig L, Knepel W. Inhibition by antidepressant drugs of cyclic AMP response element-binding protein/cyclic AMP response element-directed gene transcription. Mol. Pharmacol., 47, 1112-1118 (1995).

4) Tardito D, Perez J, Tiraboschi E, Musazzi L, Racagni G, Popoli M. Signaling pathways regulating gene expression, neuroplasticity, and neurotrophic mechanisms in the action of antidepressants: a critical overview. Pharmacol. Rev., 58, 115-134 (2006).

5) Perlis RH, Purcell S, Fagerness J, Cusin C, Yamaki L, Fava M, Smoller JW. Clinical and genetic dissection of anger expression and CREB1 polymorphisms in major depressive disorder. Biol. Psychiatry, 62, 536-540 (2007).

6) Perlis RH, Purcell S, Fava M, Fagerness J, Rush AJ, Trivedi MH, Smoller JW. Association between treatment-emergent suicidal ideation with citalopram and polymorphisms near cyclic adenosine monophosphate response element binding protein in the STAR*D study. Arch. Gen. Psychiatry, 64, 689-697 (2007).

7) Wang X, Kibschull M, Laue MM, Lichte B, Petrasch-Parwez E, Kilimann MW. Aczonin, a 550-kD putative scaffolding protein of presynaptic active zones, shares homology regions with Rim and Bassoon and binds profilin. J. Cell Biol., 147, 151-162 (1999).

8) Fenster SD, Chung WJ, Zhai R, Cases-Langhoff C, Voss B, Garner AM, Kaempf U, Kindler S, Gundelfinger ED, Garner CC. Piccolo, a presynaptic zinc finger protein structurally related to bassoon. Neuron, 25, 203-214 (2000).

9) Schuhmacher A, Mössner R, Höfels S, Pfeiffer U, Guttenthaler V, Wagner M, Schwab SG, Maier W, Zobel A. PCLO rs2522833 modulates HPA system response to antidepressant treatment in major depressive disorder. Int. J. Neuropsychopharmacol., 14, 237-245 (2011).

10) Serretti A, Chiesa A, Calati R, Massat I, Linotte S, Kasper S, Lecrubier Y, Antonijevic I, Forray C, Snyder L, Bollen J, Zohar J, De Ronchi D, Souery D, Mendlewicz J. A preliminary investigation of the influence of CREB1 gene on treatment resistance in major depression. J. Affect. Disord., 128, 56-63 (2011).

11) Perlis RH, Holt DJ, Smoller JW, Blood AJ, Lee S, Kim BW, Lee MJ, Sun M, Makris N, Kennedy DK, Rooney K, Dougherty DD, Hoge R, Rosenbaum JF, Fava M, Gusella J, Gasic GP, Breiter HC. 
Phenotype Genotype Project on Addiction and Mood Disorders. Association of a polymorphism near CREB1 with differential aversion processing in the insula of healthy participants. Arch. Gen. Psychiatry, 65, 882-892 (2008).

12) Riley WT, Treiber FA, Woods MG. Anger and hostility in depression. J. Nerv. Ment. Dis., 177, 668-674 (1989).

13) Fava GA, Kellner R, Lisansky J, Park S, Perini GI, Zielezny M. Hostility and recovery from melancholia. J. Nerv. Ment. Dis., 174, 414-417 (1986).

14) Choi-Kwon S, Han SW, Kwon SU, Kang DW, Choi JM, Kim JS. Fluoxetine treatment in poststroke depression, emotional incontinence, and anger proneness: a double-blind, placebo-controlled study. Stroke, 37, 156-161 (2006).

15) Davidson JR, Landerman LR, Farfel GM, Clary CM. Characterizing the effects of sertraline in post-traumatic stress disorder. Psychol. Med., 32, 661-670 (2002).

16) Coven E, Ni Y, Widnell KL, Chen J, Walker WH, Habener JF, Nestler EJ. Cell type-specific regulation of CREB gene expression: mutational analysis of CREB promoter activity. J. Neurochem., 71, 1865-1874 (1998).

17) Furukawa-Hibi Y, Nitta A, Fukumitsu H, Somiya H, Furukawa $S$, Nabeshima T, Yamada K. Overexpression of piccolo C2A domain induces depression-like behavior in mice. Neuroreport, 21, 1177$1181(2010)$

18) Sullivan PF, de Geus EJ, Willemsen G, James MR, Smit JH, Zandbelt T, Arolt V, Baune BT, Blackwood D, Cichon S, Coventry WL, Domschke K, Farmer A, Fava M, Gordon SD, He Q, Heath AC, Heutink P, Holsboer F, Hoogendijk WJ, Hottenga JJ, Hu Y, Kohli M, Lin D, Lucae S, Macintyre DJ, Maier W, McGhee KA, McGuffin P, Montgomery GW, Muir WJ, Nolen WA, Nöthen MM, Perlis RH, Pirlo K, Posthuma D, Rietschel M, Rizzu P, Schosser A, Smit AB, Smoller JW, Tzeng JY, van Dyck R, Verhage M, Zitman FG, Martin NG, Wray NR, Boomsma DI, Penninx BW. Genomewide association for major depressive disorder: a possible role for the presynaptic protein piccolo. Mol. Psychiatry, 14, 359-375 (2009). 